\title{
The Morphology of Alcaligenes faecalis bacteriophages
}

\author{
BY I. J. MARE, H. C. DE KLERK AND O. W. PROZESKY \\ Department of Microbiology, University of Pretoria, Pretoria, South Africa
}

(Received 2 November 1965)

\section{SUMMARY}

The morphology of seven temperate phages from lysogenic strains of Alcaligenes faecalis and two virulent phages obtained from sewage and active on this species was examined by a negative-staining technique. The phages showed a variety of morphological forms and two of them have unusual combinations of features. One (A11/A79) has a contractile tail sheath around a hollow core, but lacks the base plate, pins and tail fibres usually associated with this type of tail. The other (A5/A6) resembles the $\mathrm{C} 1, \mathrm{~F} 1$ group of coliphages but has an octahedral head and a collar. The five remaining temperate phages are similar to the $\mathrm{C} 1, \mathrm{~F} 1$ and Providence 9000/9402 group of phages. The sewage phages differ in many respects from one another and also from the temperate phages examined. At least three of the nine phages have octahedral heads.

\section{INTRODUCTION}

Temperate phages active on Alcaligenes faecalis were isolated by Moore \& Pickett (1960), but the morphology of these phages has not been described. Another series of $A$. faecalis phages derived from lysogenic strains and from sewage was reported by Mare \& Coetzee (1963), who determined the host ranges of these phages. The differentiation of $A$. faecalis from other non-sugar-fermenting bacteria is largely based on morphology and a few biochemical reactions (Bergey's Manual, 1957). The classification of $\boldsymbol{A}$. faecalis is regarded as unsatisfactory by many workers (Conn, 1942; Sarkar, Choudhury \& 'Tribedi, 1959; Moore \& Pickett, 1960). As an approach to this problem it was decided to study the morphology of the $A$. faecalis phages previously isolated in an attempt to contribute to their taxonomy and possibly to that of their hosts.

\section{METHODS}

Media. The liquid medium contained $(\%, w / v)$ : Bacto-tryptone, 1.3; $\mathrm{NaCl}, 0.8$; glucose, $0 \cdot 15$. The solid medium contained $1 \cdot 1 \%(\mathrm{w} / \mathrm{v})$ agar or $0 \cdot 6 \%(\mathrm{w} / \mathrm{v})$ agar when used as a top layer.

Bacteriophages and host organisms. The isolation of the seven temperate phages from lysogenic strains of Alcaligenes faecalis and the two virulent phages from sewage was described by Maré \& Coetzee (1963). The seven temperate phages A5/415, A20/415, A5/A6, A11/A79, A64/A62, A74/A3 and A86/A88 were propagated on A. faecalis strains NCTC 415, A6, A79, А62, А3, A88, respectively. Lysates of the two sewage phages A6 and 8764 were prepared on $A$. faecalis strains A 6 and NCTC 8764. The phages can all be differentiated by means of their host range and three of the lysogenic strains $(\mathrm{A} 5, \mathrm{~A} 20, \mathrm{~A} 11)$ can at the moment be differentiated 
by their reaction to a series of typing phages (Maré, unpublished). The general phage techniques were those of Adams (1959) and cultures were incubated at $37^{\circ}$. High titre lysates of all the phages were prepared by the modification (Adams, 1959) of the double agar layer method of Hershey, Kalmanson \& Bronfenbrenner (1943).

Electron microscopy. The phages were purified and concentrated by differential centrifugation (de Klerk, Coetzee \& Fourie, 1965). Samples of the purified phages (plaque-forming units about $1 \times 10^{11} / \mathrm{ml}$.) suspended in $0.1 \mathrm{M}$-ammonium acetate $(\mathrm{pH} \mathrm{7.2)}$ were mixed with equal volumes of neutral $2 \%(\mathrm{w} / \mathrm{v})$ potassium phosphotungstate and spread on carbon support films (Bradley, 1962). These preparations were examined with a Philips EM 200 electron microscope.

\section{RESULTS}

The dimensions of the phages are presented in Table 1. Five of the temperate phages A5/415, A20/415, A64/A62, A74/A3 and A86/A88 are similar in morphology; phage A64/A62 is shown in Pl. 1, fig. 1. Their heads have regular hexagonal outlines and their tails are long, thin, non-contractile, with pointed ends, and they lack cross-striations. They have no necks or collars; no tail fibres were seen. Phage A 86/A88 is larger than the others of this group. These phages are larger than the providence phage 9000/9402 (Prozesky, de Klerk \& Coetzee, 1965) and small er

Table 1. Dimensions of alcaligenes bacteriophages

$\begin{array}{lcccc}\text { Phage } & \begin{array}{c}\text { Head* } \\ (\AA)\end{array} & \begin{array}{c}\text { Tail } \\ \text { length } \\ (\AA)\end{array} & \begin{array}{c}\text { Tail } \\ \text { width } \\ (\AA)\end{array} & \begin{array}{c}\text { Overall } \\ \text { length } \\ (\AA)\end{array} \\ \text { A5/415 } & 750 & 2400 & 100 & 3150 \\ \text { A20/415 } & 750 & 2400 & 100 & 3150 \\ \text { A5/A6 } & 750 & 2400 & 90 & 3150 \\ \text { A11/A79 } & 650 & 1300 & 190 & 1950 \\ \text { A64/A62 } & 750 & 2500 & 100 & 3250 \\ \text { A74/A3 } & 750 & 2500 & 120 & 3250 \\ \text { A86/A88 } & 800 & 2500 & 170 & 3300 \\ \text { A6 } & 900 & 1100 & 160 & 2000 \\ \text { 8764 } & 600 & 1700 & 110 & 2300\end{array}$

* Dimensions between apices are given. Figures are the mean of six to twelve measurements.

than the $\mathrm{C} 1, \mathrm{~F} 1$ group of coliphages (Bradley, $1963 a$ ), both of which they resemble. Phage A5/A6 (Pl. 1, fig. 2) differs from the first group of five phages in that it has a neck and a collar about $120 \AA$ in width. Its head is larger than most of those of the first group of phages and is octahedral in shape (Pl. 1, fig. 3). The remaining temperate phage, A11/A79 ( $\mathrm{Pl}$. 1, figs. 4,5$)$ has a small head with a regular hexagonal outline. The tail consists of a hollow core surrounded by a contractile sheath and it is attached to the head by a short neck which has no collar. This phage lacks a base plate; no tail pins or fibres were seen. It resembles typhoid phage $\phi 2$ (Bradley \& Kay, 1960) which has, however, a distinct base plate without pins. The sewage phage A6 (PI. 1, figs. 6, 7) has a large octahedral head. Its other features also resemble those of coli-typhoid phages $\phi 2$ and E1 (Bradley, 1963a) and pseudomonas phage 12S (Bradley, 1963b). The tail has a hollow core and a contractile sheath in which subunits are visible; no cross-striations. No base plate is evident, 
but an indistinct cluster of fibres like those of phage $12 \mathrm{~S}$ (Bradley, 1963b) moves with the contractile sheath. The other sewage phage 8764 (Pl. 1, fig. 8) has a small octahedral head and a long, thin, non-contractile tail without cross-striations. No neck or collar is present and the pointed tail tip has a cluster of delicate fibres around it. This phage resembles coliphages $\beta 4$ and $\gamma 2$ (Bradley, 1963 $a$ ). Three of the phages (A5/A6, A6, 8764) have octahedral heads. The head shapes of the remaining phages could not be determined. Many of the capsids have an uneven rough appearance suggestive of arrays of capsomeres, but neither their shape nor their packing arrangements could be resolved. None of the tails show cross-striations and they appear to consist of small tightly packed subunits.

\section{DISCUSSION}

Most of the phages examined resemble certain coli, typhoid, pseudomonas or providence phages, but two phages show unusual combinations of features. Phage A11/A79 has a tail with a contractile sheath but lacks all the appendages usually associated with this type of tail structure (Bradley \& Kay, 1960; Prozesky et al. 1965). Phage A5/A6 has a single collar and an octahedral head-shape. This combination differs from phage ZG/3 A (Bradley, 1964b) which has a collar and a head like that of coliphage T2, and also from phage PS4 (Matthews \& Bradley, 1964) which has a double collar. Other phages with long, thin, non-contractile tails do not have collars (Bradley, 1964b). All the phages are large and three have octahedral heads. The micrographs do not reveal the geometrical form of the other heads, but their size favours the octahedral shape (Matthews \& Bradley, 1964). A striking feature of these phages, both with and without tail sheaths, is the absence of cross-striation of the tails. Many phages previously described with the same general morphology possess cross-striations (Bradley \& Kay, 1960; Bradley, $1963 a$, $b$; Prozesky et al. 1965). The techniques employed were those of Prozesky et al. (1965) and the absence of cross-striations may be due to the packing of the small subunits, so that striations are below the resolution obtainable. Five of the temperate phages described here are similar to one another but originated in different strains of Alcaligenes faecalis. This may be of some importance in the taxonomy of these phages, although as mentioned above phages which attack this family are basically typical of 'enterophages'. Unlike the filamentous phages of Escherichia coli which are specific for male strains of this species (Bradley, 1964a, $b$ ) the phages studied here failed to show a morphology peculiar to $A$. faecalis and in this respect do not contribute to its classification.

This work was supported by grants from the South African Council for Scientific and Industrial Research to Professor J. N. Coetzee.

\section{REFERENCES}

Adams, M. H. (1959). Bacteriophages. New York: Interscience Publishers, Inc.

Bergey's Manual of Determinative Bacteriology (1957). 7th ed. Ed. by R. S. Breed, E. G. D. Murray and N. R. Smith. London: Baillière, Tindall and Cox, Ltd.

Bradley, D. E. (1962). A study of the negative staining process. J. gen. Microbiol. 29, 503. Bradley, D. E. (1963a). The structure of coliphages. J. gen. Microbiol. 31, 435. 
Bradley, D. E. (1963b). The structure of some Staphylococcus and Pseudomonas phages. J. Ultrastructure Res. 8, 552.

BradLey, D. E. (1964a). Some preliminary observations on filamentous and RNA bacteriophages. J. Ultrastructure Res. 10, 385.

Bradley, D. E. $(1964 b)$. The structure of some bacteriophages associated with male strains of Escherichia coli. J. gen. Microbiol. 35, 471.

Bradley, D. E. \& KAY, D. (1960). The fine structure of bacteriophages. J. gen. Microbiol. 23, 553.

ConN, H. J. (1942). Validity of the genus Alcaligenes. J. Bact. 44, 353.

Hershey, A. D., Kalmanson, G. R. \& Bronfenbrenner, J. (1943). Quantitative methods in the study of the phage-antiphage reaction. J. Immunol. 46, 267.

De Klerk, H. C., Coetzee, J. N. \& Fourie, J. T. (1965). The fine structure of Lactobacillus bacteriophages. J. gen. Microbiol. 38, 35.

Maré, I. J. \& Coetzee, J. N. (1963). Lysogeny in Alcaligenes faecalis and the host-range of $A$. faecalis bacteriophages. Nature, Lond. 197, 1322.

Matthews, M. A. \& Bradiey, D. E. (1964). Preliminary observations on two new bacteriophages from Pseudomonas and Serratia. Proc. Eur. Reg. Conf. electron microscopy, Prague, 3B, 543.

Moore, H. B. \& Picketr, M. J. (1960). Organisms resembling Alcaligenes faecalis. Can. J. Microbiol. 6, 43.

Prozesky, O. W., de Krerk, H. C. \& Coetzee, J. N. (1965). The morphology of Proteus bacteriophages. J. gen. Microbiol. 41, 29.

Sarkar, J.K., Choudhury, B. \& Tribedi, B.P.(1959). Alcaligenes faecalis-its systematic study. Indian J. med. Res. 47, 1.

\section{EXPLANATION OF PLATE}

The magnification in figs. $1-7$ is $\times 270,000$ and in fig. 8 is $\times 350,000$. All phages in ammonium acetate and phosphotungstate.

Fig. 1. Phage A64/A62.

Fig. 2. Phage A5/A6 showing collar.

Fig. 3. Phage A5/A6 showing octahedral head and collar.

Fig. 4. Phage A11/A79.

Fig. 5. Phage A11/A79 with contracted tail sheath.

Fig. 6. Phage A6.

Fig. 7. Phage A6 with contracted tail sheath.

Fig. 8. Phage 8764 . 

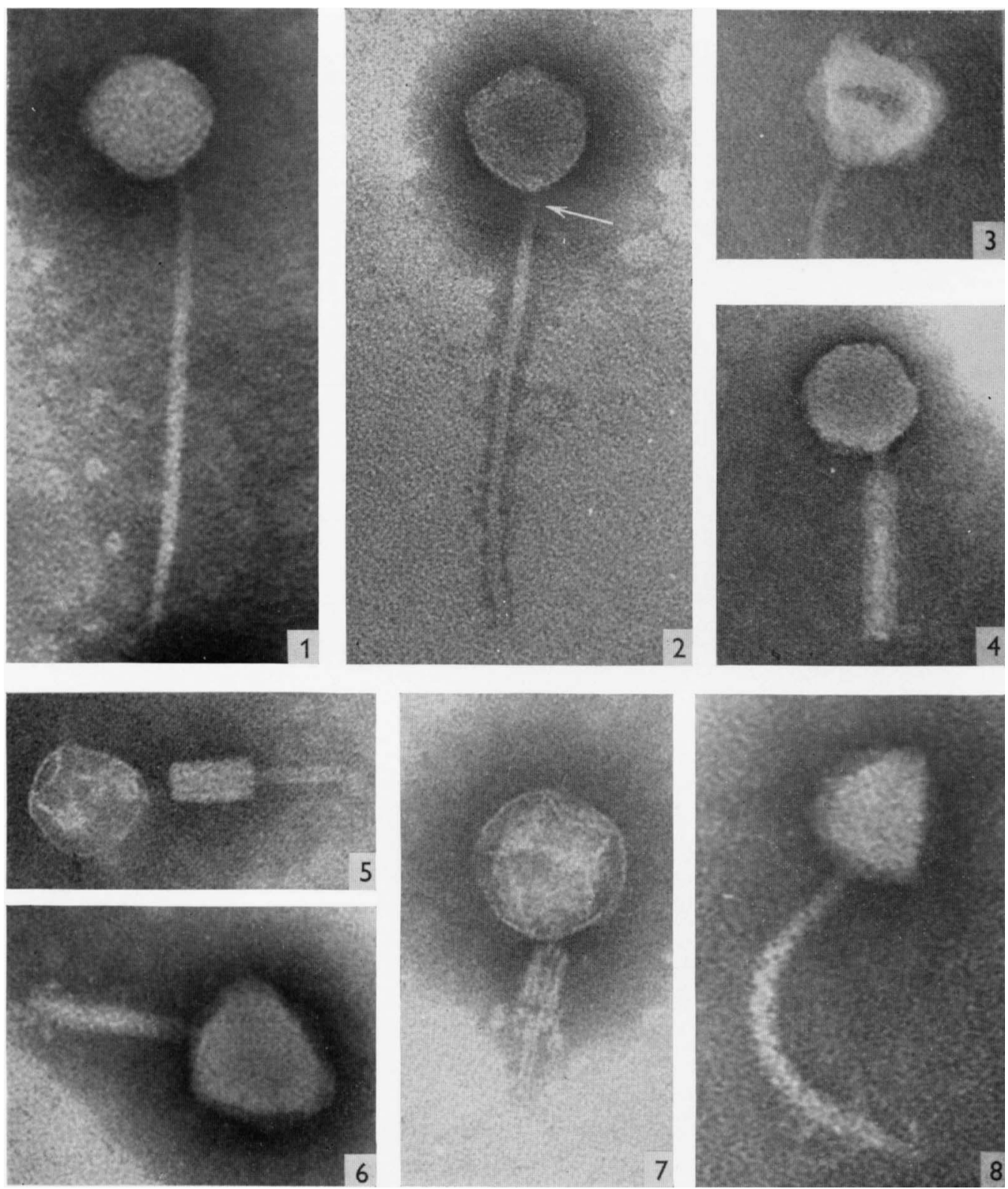